\title{
Free piston linear generator in comparison to other range- extender technologies
}

\author{
Roman Virsik, Alex Heron \\ Institute of Vehicle Concepts, German Aerospace Center, Pfaffenwaldring 38-40 \\ Stuttgart, 70569, Germany \\ roman.virsik@dlr.de,alex.heron@dlr.de
}

\begin{abstract}
The free piston linear generator is a new range-extender technology. It converts chemical energy into electrical energy by means of a combustion process and linear generator. Thereby the technology aims to have better properties than other range extenders. Therefore this publication deals with the explanation of the concept and the characteristics of a free piston linear generator and a comparison to other technologies. In order to compare the range extender systems, fuel cells, micro gas turbine and otto/wankel combustion, will briefly be presented, before being compared to the free piston linear generator.
\end{abstract}

Keywords: Free-piston linear generator, wankel, otto, engine, range extender, fuel cell

\section{Introduction}

The vehicle market is slowly adapting to the facts that there is a growing amount of consumers that would like to have real alternative cars [1]. Most Hybrid cars do not create the benefit that could be expected by the spec sheet, as they are mainly optimized to benefit in the standard cycles.

The vehicle concepts that would really have an impact to the CO2 output are battery electric vehicles with or without range extenders as well as vehicles especially designed as series hybrids.

A reason for the lack of these vehicles is the absence of a promising or revolutionary technology in the field. The free piston linear generator (FPLG) was developed with the aim to fill this void. The idea of converting chemical energy into electrical energy by means of a combustion process is not new and free piston concepts themselves have been around for a while. Still the properties of a FPLG, as described in [2], e.g. the high degree of efficiency and its independence of the load level are inherent in the design of the FPLG, are promising.

The other, more State-of-the-Art, range-extender technologies that are to be compared are fuel cell, micro gas turbine and wankel-/ottomotor generators. In the comparison an electrical output of $20 \mathrm{~kW}$ is specified as design size for the range extender.

\section{Free-piston linear generator}

In the field of free piston motors the free piston linear generator is a promising design. The system described in the following is developed in the German aerospace centre (DLR). The proof of concept took place in Stuttgart at the end of 2012. This demonstrated that the control of a free piston engine can be designed to allow robust operation even with large combustion variations [5]. 


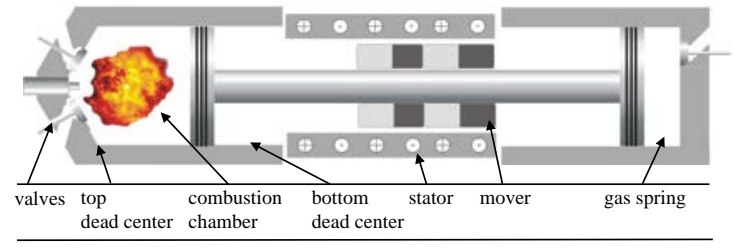

Figure 1: Illustration of the principle of the free-piston linear generator

\subsection{Design}

The free-piston linear generator module in Figure 1 consists of a piston rod connected with a piston on either side, cylinders around the pistons and a linear generator. At one end the cylinder forms the combustion chamber which is powered by a liquid or gaseous energy carrier. The gas exchange of the combustion chamber is controlled by electrically actuated valves in the cylinder head. The opposite cylinder creates an adjustable gas spring. The spring rate of the gas spring is adjusted by means of regulating the air mass in the cylinder.

The linear generator sits between the two cylinders. Its mover is mounted on the piston rod. The mover consists of permanent magnets glued into a plastic matrix and additionally secured by a fibre-glass reinforced bandage. Stators with integrated generator windings and a cooling system enclose the mover and complete the linear generator.

\subsection{Operation}

The load cycle begins with the combustion piston at the top dead centre (TDC). The chamber is filled with a compressed, flammable mixture previously introduced into the combustion chamber which is ignited by a spark plug. The two pistons, the rod and the mover (double piston system) move towards the bottom dead centre (BDC, direction of gas spring). The motion of mover and its magnets induces a voltage in the coils of the stator which drives a corresponding electric current. About half of the energy released in the combustion is converted during the movement from TDC to BDC by the linear generator. The other half is stored in the gas spring and extracted on the return stroke (BDC to TDC) of the double piston system. While the gas spring is compressed (the combustion piston is at its BDC) the combustion chamber is actively scavenged with charged, fresh air. After injection of fuel the mixture is compressed and as the double piston system arrives at the TDC, the next load cycle can begin. The variation of the output power can be achieved by adjustment of the inlet pressure and injection period in combination with the stroke. Thereby the stroke is controlled by the air mass in the gas spring. The mechanical frequency of the double piston system only varies slightly between multiple operating points.

\subsection{Characteristics}

A FPLG system for use as range extender would consist of two of the above described modules, to allow for a full mass compensation. Schematic the system would look like [2] (a). The most advanced solution is the central combustion chamber (b). For such systems in depth analysis, simulation and estimation were carried out during the REXEL study [4]. Yet since the proof of concept of the module new estimates are being made in the DLR. Due to the measurements and information gathered some properties can now be described with higher precision.

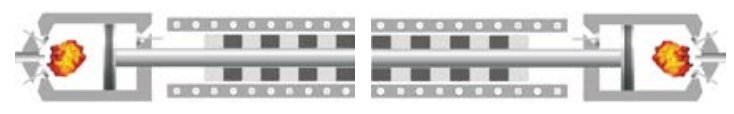

(a) dual module system

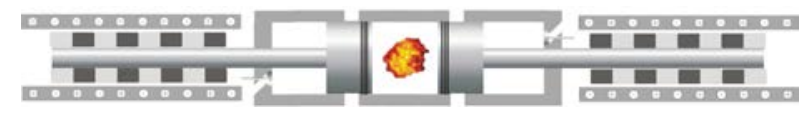

(b) central combustion system

Figure 2: Free piston linear generator systems

\subsubsection{Mass and Power Density}

The REXEL study estimates the weight of a free piston linear generator with a central combustion unit at $55.9 \mathrm{~kg}$. This weight involves the power electronics needed to run the FPLG. The power density for this build up is $350 \mathrm{~W} / \mathrm{kg}$. The more recent research leads to a correction of the estimate to $320 \mathrm{~W} / \mathrm{kg}$, as the combustion unit needed to be estimated heavier.

\subsubsection{Packaging}

An advantage of the FPLG is the freedom of alignment. There are many ways to connect the FPLG subsystems. By placing the linear generators next to the combustion chamber and gas spring a short alignment as shown in the Figure 2 is possible. All possibilities only need a height of 15 $\mathrm{cm}$; therefore integration in the floor of a vehicle is an option. In the most recent estimates the FPLG 
with a central combustion unit and all auxiliaries can achieve a volumetric density of up to 470 $\mathrm{W} / \mathrm{l}$.

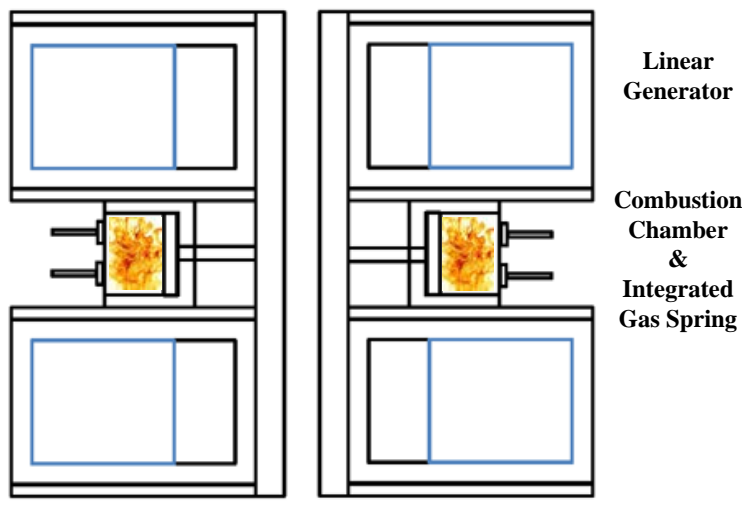

Figure 2: FPLG system short alignment

\subsubsection{Efficiency}

Former experimental studies showed that the combustion unit could easily achieve an efficiency of 36\% [5] and with the proof of concept system an efficiency of 33\% has been measured in the combustion unit, without any optimization effort.

Based on this knowledge the most recent estimate for the FPLG from fuel to electric is $36,6 \%$. The regarded system has a central combustion chamber with integrated gas springs, seen in Figure 2 (b) and takes all auxiliaries into consideration.

Additionally the beneficial efficiency is not limited to one optimal point. Due to the variability of the system, lower load points do not lead to a large reduction of efficiency.

\subsubsection{Production cost}

The REXEL study named a very progressive price of just over $1500 €$ per unit at a production amount of 100.000 pieces per year. $2100 €$ is a more recent and conservative estimation of the production cost. Both cases regarded a central combustion chamber and the complete surrounding system.

\subsubsection{Scalability}

Every component of the FPLG is scalable for other power requirements. To adapt the linear generator the area of the stator and the mover has to be changed. For the gas spring and the combustion unit the cylinder is significant. The capacity is adapted by changing the bore or the stroke. To get more power out of a combustion unit without resizing the cylinder a stronger turbocharger can be used. This option still may need constructive changes to the combustion unit to allow higher pressures.

Furthermore there is the possibility for a parallel connection of multiple FPLGs. In a vehicle with such a solution only necessary amount of FPLGs would be in use at any given time. Thus there is less need to adapt the FPLG to every car concept.

\subsubsection{NVH}

The NVH behaviour of the FPLG is aimed to be low. As described above each system consists of two modules. By synchronizing these all free inertial mass forces are eliminated. Therefore no vibrations are transferred to the vehicle body. Only the turbocharger and exhaust need standard soundproofing.

\subsubsection{Flexibility of fuel}

As the FPLG has no crankshaft the compression ratio is adjustable. An appropriate fuel suppy system therefore would allow many sorts of fuels (petrol, diesel, natural gas, sun fuel, synthetic fuel, hydrogen, etc.). The fuels can be used without any constructional changes in the combustion unit, as the adaption of the compression ratio is design inherit. Thus the fuel can be used at their maximum compression ratio, allowing the highest possible efficiency.

\subsubsection{Emissions}

The challenges a 2-stroke petrol combustion process face in regards to emissions are the mixture preparation and the avoidance of $\mathrm{HC}$ emissions during the simultaneous opening of the intake and exhaust valves. To prevent the HC emissions the FPLG uses direct injection after all valves are closed. With a stoichiometric combustion a standard three-way catalytic converter can be used. For this purpose the short circuit flow has to be minimized. Otherwise a NOx storage catalytic converter is necessary.

As mentioned above the FPLG has more degrees of freedom than normal engines. This allows the implementation of self-ignition combustion (HCCI). For part load points HCCI has the advantages of very high efficiency and very low emissions [6].

\subsubsection{Dynamics}

The dynamic adjustment of the electrical power output of the FPLG is achieved by varying the fuel injection period and the pressures in the combustion and the gas spring component. A 
simulation of the response shows that a jump to $20 \mathrm{~kW}$ is achieved in about 0.6s. When the control strategy is optimized the response of the FPLG should be even better.

Table 1: Summary of FPLG characteristics

\begin{tabular}{|l|l|}
\hline Criteria & Assessment \\
\hline efficiency & $36.6 \%$ \\
\hline packaging & $470 \mathrm{~W} / \mathrm{l}$ without auxiliary units \\
\hline power density & $320 \mathrm{~W} / \mathrm{kg}$ \\
\hline cost & $2000 €$ \\
\hline emissions & 3-way-catalyst \\
\hline flexibility of fuel & many fuels with full potential \\
\hline $\begin{array}{l}\text { noise - vibration } \\
\text { harshness }\end{array}$ & mid (full mass compensation) \\
\hline scalability & good \\
\hline dynamics & Fast, $<1 \mathrm{~s}$ \\
\hline
\end{tabular}

\section{Fuel Cell}

\subsection{Introduction}

Fuel cells convert chemical energy directly into electrical energy. The numerous fuel cell technologies differ in the electrolytes used and fuel types they can convert. The most common fuel is hydrogen which is also used in the polymer electrolyte membrane fuel cells (PEMFC). Of the available fuel cell technologies only PEM is sophisticated enough to be regarded for use as range extender. It has to be noted, that a disadvantage especially fuel cells have is the storage and the missing infrastructure for hydrogen.

\subsection{Characteristics}

The basic information from the REXEL study to fuel cells was briefly updated to create the characteristic. The ideal efficiency of a fuel cell is $83.3 \%$. Although the state of the art is not as high and the auxiliaries of a fuel cell reduce the efficiency, fuel cells are a most efficient system [7]. The direct energy conversion also creates the advantage, that there is no need for large or heavy moving parts. Only auxiliary units like air supply produce NVH through rotating parts. Rubber bearings and other simple instruments help minimize the problem.

A further tool to reduce NVH could be a change in the packaging. The often used rectangular cases for fuel cells are used because of the simplicity and the small numbers in production.
Yet there is no reason why the systems should not be integrated into a vehicle design and thereby add some flexibility to the good packaging.

Besides the low production amount the cost of fuel cells are very high because they have very expensive parts, e.g. the electrodes made of platinum, which are used in the fuel cell stacks. Thus the fuel cell stacks makes about $50 \%$ of the whole system costs. A lot of research therefore is aimed at lowering the price [4].

Table 2: Characteristics of fuel cells

\begin{tabular}{|l|l|}
\hline Criteria & Assessment \\
\hline efficiency & Up to 59\% [6] \\
\hline packaging & $1100 \mathrm{~W} / \mathrm{l}$ without auxiliary units \\
\hline power density & $200-885 \mathrm{~W} / \mathrm{kg}$ \\
\hline cost & $40000 €[4]$ \\
\hline emissions & Water and little ppm of hydrogen \\
\hline flexibility of fuel & None \\
\hline $\begin{array}{l}\text { noise vibration } \\
\text { harshness }\end{array}$ & Very calm \\
\hline scalability & mid-good \\
\hline dynamics & Mid-good, 3-30 s \\
\hline
\end{tabular}

In regards to scalability, connecting fuel cell stacks in a parallel and/or a serial fashion can be easily realised. However every variation of stack combinations needs its specific fuel supply and operating strategies. This leads to an own design and control system for each desired output power. The fuel supply and control system also determine the dynamic behaviour of a fuel cell. Delivering instantaneous energy is possible; however it is not an optimal solution if the system is optimized for efficiency in a long term operation point. Therefore the manufacturers defined maximum current changes. They can allow a jump to $90 \%$ power output within seconds. In a range extender system faster dynamics could be carried by the battery.

\section{Micro gas turbine}

\subsection{Introduction}

Micro gas turbines are thermal turbo machines with a continuous combustion. They consist of a single stage compressor, a combustion chamber, a single stage turbine and a recuperator. The mechanical power output of the turbine can be converted by a generator to electrical energy, in this configuration the system is also known as a turbine range extender (TRE). 
Most advantages are due to the simplicity of the system, with the single stage compressor and turbine connected to the mover there is only one moving part.

In comparison to the other system there are already commercially distributed products [8].

\subsection{Characteristics}

The continuous burning in micro gas turbines leads to an advantage since very low emissions are ejected and fuel flexibility is possible. Therefore no exhaust after treatment is necessary. The continuous combustion also allows for easy optimization in regards to efficiency. However the efficiency is significantly influenced by the use of a recuperator. So although efficient recuperators are complex and need a large volume the strong loss in power density is accepted to keep the overall TRE efficiency high.

As mentioned above, realizing a system with only one movable component results in high reliability and availability. Meanwhile the maintenance costs are low due to long maintenance intervals. If it is possible to omit the oil circuit and cooling system the TRE-unit becomes a lightweight and rather inexpensive system.

The battery unit combined with the TRE would need to cover the dynamic loads, as the continuous combustion doesn't allow the TRE to change load point very fast. Yet the steady rotation results in smooth running, which can easy be silenced to enhance driving comfort.

As the Capstone Drive Solution with a C30 turbine is a TRE with volume production and an electric output close to the desired $20 \mathrm{~kW}$, its values of the system are used for the characterization in Table 3.

Table 3: characteristics of Turbine range extender

\begin{tabular}{|l|l|}
\hline Criteria & Assessment \\
\hline efficiency & $25-35 \%$ \\
\hline packaging & $95 \mathrm{~W} / \mathrm{l}$ \\
\hline power density & $400 \mathrm{~W} / \mathrm{kg}$ \\
\hline cost & cheap due to mass production \\
\hline emissions & $\begin{array}{l}\text { natural gas: NOx 9 ppmv, CO 50 } \\
\text { ppmv } \\
\text { fluid fuel: NOx 35 ppmv, CO 15 } \\
\text { ppmv }\end{array}$ \\
\hline flexibility of fuel & is possible \\
\hline $\begin{array}{l}\text { noise }- \\
\text { harshness }\end{array}$ & 65 dB \\
\hline scalability & mid-good \\
\hline dynamics & slow, 10-90 s \\
\hline
\end{tabular}

\section{Internal combustion engine}

\subsection{Introduction}

Internal combustion engines are very common in the field of ground vehicles. Through history many types of these engines were developed. For use as a range extender the Wankel engine and the 4 stroke otto-cycle engine are regarded as the most interesting options in this chapter. Diesel engines could also be a viable option, yet they are not considered, because there is no experience with low power diesel engines that are also optimized for weight and efficiency.

An otto-engine range extender is the combination of a small, 4-stroke combustion engine with a rotational generator connected to the crankshaft. The wankel system allows for a connection of the generator directly to the rotating piston.

\subsection{Characteristics}

As the piston of the Wankel engine, seen in Figure 3 , rotates and can be directly connected to a generator, the system can run very calm. However the rotary piston has efficiency disadvantages due to blowby losses during the combustion process. Also the engine is optimised for a single load point and has lower efficiency at other load points.

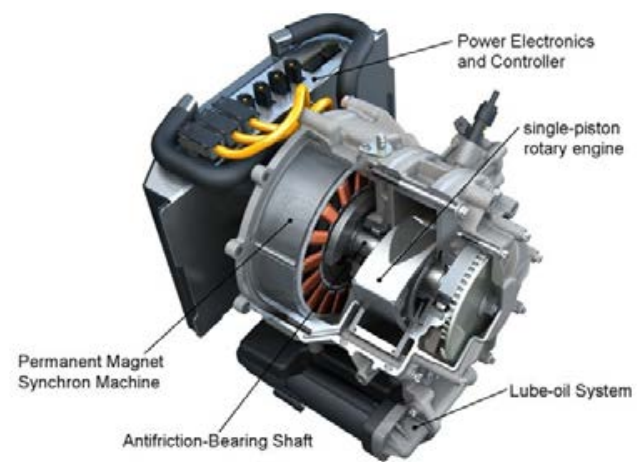

Figure 3: AVL List- Wankel REX system

The direct connection allows the Wankel system to have a high volumetric and specific power density. Due to the separate areas for compression and combustion the system also has optimal requirements to use a variety of fuels including hydrogen.

Otto-cycle systems reach their highest efficiency only in one operating point. At different load points the throttling losses decrease the efficiency. Through the large amount of know-how and with the sole use as range extender in mind a reduction 
of the standard NVH to a low level is possible for an Otto system.

The use of a selection of fuels can be realized in a 4-Stroke Otto. However the hardware optimization is limited by the fuel that has the lowest octane rating, therefore wasting potential of the other fuels.

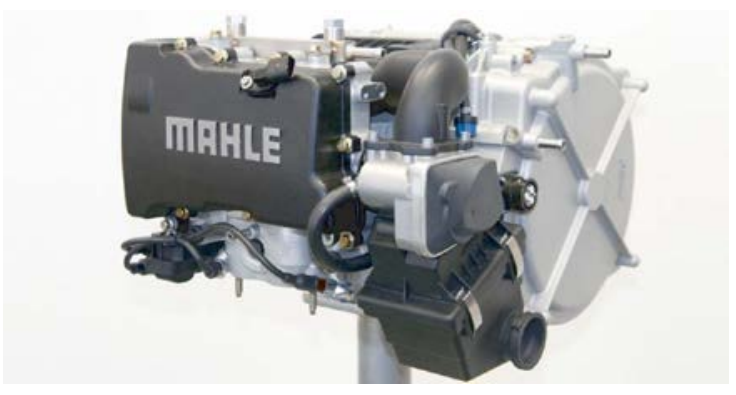

Figure 4: Mahle- 30kw, 4 stroke, Otto Rex-system

The high level of specialization of Otto systems also allows for example the Mahle system in Figure 4 to achieve $458 \mathrm{~W} / \mathrm{l}$ (without cooling). However similar to the Wankel it is highly integrated and has little to no possibilities for simple variation [9].

Both systems need standard after treatment for the exhaust gas. And by enlarging the displacement, adding additional cylinders or charging the inlet both systems can be scaled to a diversity of power outputs.

Table 4: ICE characteristics

\begin{tabular}{|l|l|}
\hline Criteria & Assessment \\
\hline efficiency & $19-31 \%$ \\
\hline packaging* & $458-640 \mathrm{~W} / \mathrm{l}$ \\
\hline power density* & $500-830 \mathrm{~W} / \mathrm{kg}$ \\
\hline cost & cheap due to mass production \\
\hline emissions & Need a 3 way catalyst \\
\hline flexibility of fuel & is possible \\
\hline $\begin{array}{l}\text { noise }- \\
\text { harshness }\end{array}$ & calm \\
\hline scalability & good \\
\hline dynamics & fast, < 1 s \\
\hline *cooling system and possibly other auxiliaries not included
\end{tabular}

\section{Comparison}

\subsection{FPLG - PEMFC}

A FPLG system can be designed to run on a selection of fuels while a PEM fuel cell needs hydrogen. As the infrastructure for hydrogen is not yet widespread this is a disadvantage for the fuel cell. Also fuel cells systems are more expensive and less dynamic than FPLGs.

Therefore, although fuel cells have a better efficiency and higher specific and volumetric power density, they still are viewed as solution for the mid to distant future. Meanwhile the FPLG with its possibility to run on several fuels, including hydrogen, can be viewed as a technology to bridge the gap between present and future.

\subsection{FPLG - TRE}

In comparison to turbine range extenders the FPLG has a higher efficiency potential. Furthermore the volumetric power density and dynamic speed of a FPLG system is higher. The faster dynamics lead to less strain for the battery system which could reduce battery complexity and costs. As the FPLG is similar or better than turbine systems in many properties, turbine systems are only interesting in specific circumstances. For example if low weight and $\mathrm{NVH}$ are very important aspects and there is enough room for a TRE, it would be considered.

\subsection{FPLG - ICE}

The differences between the FPLG and Otto/Wankel combustion engines are harder to determine. One reason is that the commercially available range extender systems do not clearly define the system boarders. Still it is determined, that the FPLG can achieve a higher efficiency and can utilize a diversity of fuels to their full potential.

The specific and volumetric power density of the FPLG is very similar to Otto systems; however the FPLG allows a better integration in the vehicle floor due to the low height. Only the Wankel is noticeably smaller a lighter, yet has an even larger efficiency deficit.

A FPLG may cost slightly more than a comparable Otto/Wankel, but if in use often, the lower fuel consumption would equal the price out.

For vehicle concepts with range extender system that are in service on a regular basis, or series hybrid concepts the FPLG would be the the better option in comparison to Otto/Wankel systems. For 
seldom used range extenders the FLPG may not pay off the higher investment.

\section{Conclusion}

In a developed state a free piston linear generator system can cover a large amount of tasks that are heading towards the automobile industry in the next decades. The FPLG can be used in a variety of vehicle concepts in a more efficient manner than other technologies; solely some specific concepts would prefer another solution. Even the possible development towards hydrogen based mobility is supported by the concept of the free piston linear generator.

\section{References}

[1] H.E. Friedrich, B. Frieske, Trends in der Fahrzeugtechnik vor dem Hintergrund politischer Vorgaben und erwarteter Marktentwicklung, Deutsches Zentrum für Luft- und Raumfahrt, Sindelfingen, 2012 Dr. Markus Gräf, Dr. Peter Treffinger, Sven-Erik Pohl, Frank Rinderknecht: "Investigation of a high efficient Free Piston Linear Generator with variable Stroke and variable Compression Ratio”, 2007, WEVA Journal Volume 1.

[2] Dr. Markus Gräf, Dr. Peter Treffinger, SvenErik Pohl, Frank Rinderknecht: "Investigation of a high efficient Free Piston Linear Generator with variable Stroke and variable Compression Ratio”, 2007, WEVA Journal Volume 1.

[3] F. Kock, A. Heron, F. Rinderknecht, H. E. Friedrich, „The Free-Piston Linear Generator FPLG af-ter the Proof of Concept: Potentials and Challenges Yesterday, Today and Tomor-row“, MTZ 10/2013

[4] C. Ferrari, S. Offinger, M.Schier, F.Philipps, et al., "Studie zu Range Extender Konzepten für den Einsatz in einem batterieelektrischen Fahrzeug - REXEL“, DLR, Hacker Media, Stuttgart, 2012

[5] C. Ferrari "Entwicklung und Untersuchung eines Freikolbenlineargeneratorsystems unter besonderer Berücksichtigung des verbrennungsmotorischen Teilsystems mit Hilfe eines neuartigen vollvariablen Prüfstands“, PhD Thesis, 2012.

[6] B. Johansson, „HCCI - the optimum combustion process for IC engines?”, Proceedings of the European Combustion Meeting, 2005
[7] U.S. Department of Energy, "Hydrogen, Fuel Cells \& Infrastructure Technologies Program Multi-Year Research, Development and Demonstration Plan,” Updated 2012

[8] Capstone Turbien Coorparation, "CR30 MicroTurbine - Renewable Fuels”, product data sheet, http://capstoneturbine.com

[9] Mahle Group, „, Mahle compact range extender engine“, Mahle Product Information, 04/2011

\section{Authors}

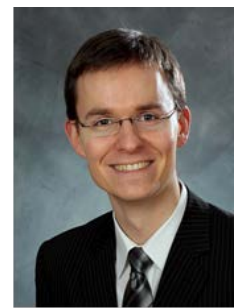

Roman Virsik received his Diploma degree from University of Stuttgart in 2011. Since then, he has been a research associate at German Aerospace Center, Institute of Vehicle Concepts. He has been working in the fields of alternative energy converters and combustion development, in particular on the free piston linear generator.

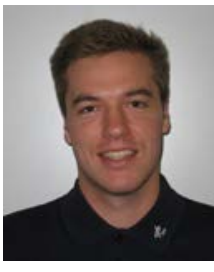

After graduating from the University of Stuttgart, Alex Heron started working at the German Aerospace Center. His work regarding the free piston linear generator includes system simulation, development of the control system and support of the test rig. 